\title{
Additive manufacturing in orthopaedics: Clinical implications
}

\author{
TL Hilton MBChB(UCT), DA(SA), DipPEC(SA), FCOrth(SA), MMed(UCT) \\ Orthopaedic Consultant, Groote Schuur \& Vincent Pallotti Hospitals, Cape Town. \\ Affiliated to the University of Cape Town \\ N Campbell MSc(Med) Biomedical Engineering (UCT) \\ Managing Director, LRS Implants, Cape Town \\ K Hosking MBChB(UCT), FCOrth(SA) \\ Orthopaedic Consultant, Groote Schuur \& Vincent Pallotti Hospitals, Cape Town. \\ Affiliated to the University of Cape Town
}

\author{
Corresponding author: \\ Dr TL Hilton \\ 11 Clive Street \\ Vredehoek \\ 8000 Cape Town \\ Western Cape, South Africa \\ Email: tlhilton@hotmail.com
}

Cell: 0027 (82) 7967608

\begin{abstract}
Background: The reconstruction of complex pelvic trauma or developmental bone abnormalities is challenging as it involves in-depth understanding of a complex three-dimensional structure. Advances in medical imaging and rapid prototyping allow for detailed pre-operative planning and manufacture of planning models, custom jigs and prostheses to make this type of surgery manageable with good results.

Methods: We report the reconstruction of a hip and proximal femur using planning models, jigs and custom prostheses produced by rapid prototyping methods. These tools helped to solve a complex problem and produced a good functional result for the patient.

Results: In this case report the patient underwent the reconstruction of her right hip joint. She was unable to mobilise well independently prior to the surgery. The surgery provided her with a stable and functional hip joint. This allows her to mobilise independently with an external prosthesis. One year down the line she has a Fair MSTS score (14 of 30).

Conclusion: Advances in medical imagining and rapid prototyping have produced planning and operative tools with which surgeons are able to solve complex problems safely and with good result. This technology has widespread use not only in orthopaedics but other surgical disciplines, and with increasing availability and improved cost effectiveness will be used more frequently in the future.
\end{abstract}

Level of evidence: Level V (case report)

Key words: pelvic reconstruction, proximal femoral focal deficiency, 3D printing, rapid prototyping

\section{Introduction}

The reconstruction of complex pelvic trauma or developmental bone deformities is problematic with little in the literature by way of guidance..$^{1,2}$ The primary goals of achieving a long-term, functioning and pain-free hip joint after pelvic reconstruction are to recreate the integrity and symmetry of the bony pelvic ring and to balance the soft tissues carefully. ${ }^{3}$ Pre-operative planning is essential in order to achieve these goals and must be based on a precise understanding of the deformity. Two-dimensional imaging often falls short in conveying enough information about the complex threedimensional (3D) anatomy of the pelvis. The 3D capabilities of computed tomography (CT) and magnetic resonance imaging (MRI) can expand these capabilities significantly., However, proprietary hardware, software and services are known to be extremely costly when customised reconstructions are required. ${ }^{3}$ This case report demonstrates that the use of $3 \mathrm{D}$ printing and rapid prototyping can provide affordable and personalised templates and implants, which 


\begin{tabular}{|l|l|}
\hline Table I: Definition of terms \\
\hline 3D printing & $\begin{array}{l}\text { A process for making a physical object from a } \\
\text { three-dimensional digital model, typically by } \\
\text { laying down many successive thin layers of a } \\
\text { material }\end{array}$ \\
\hline $\begin{array}{l}\text { Additive } \\
\text { manufacturing }\end{array}$ & $\begin{array}{l}\text { The process of joining materials to make objects } \\
\text { from 3D model data, usually layer upon layer } \\
\text { as opposed to subtractive manufacturing } \\
\text { methodologies }\end{array}$ \\
\hline $\begin{array}{l}\text { Rapid } \\
\text { prototyping }\end{array}$ & $\begin{array}{l}\text { A group of techniques used to quickly fabricate } \\
\text { a scale model of a physical part or assembly } \\
\text { using three-dimensional computer aided } \\
\text { design (CAD) data. Construction of the part or } \\
\text { assembly is usually done using 3D printing or } \\
\text { 'additive layer manufacturing' technology. }\end{array}$ \\
\hline
\end{tabular}

are useful in planning and performing these technically difficult surgeries ${ }^{6}$ We describe below an example where this technology was used to assist in the reconstruction of a severely dysplastic acetabulum. Table I defines the terms used.

\section{Case report}

A 53-year-old woman was referred to our unit for management of her right leg problem. She was born with an Aitken type $\mathrm{C}$ proximal focal femoral deficiency (PFFD). As a child she underwent a stump plasty, which included the fusion of her knee joint and a transtibial amputation. However, she developed a fixed flexion contracture of her right hip, which, together with an unstable hip joint, made prosthetic use and mobilisation impossible.

On examination, she was assessed as having a telescoping right hip joint that was painful on weightbearing and a fixed flexion contracture of 40 degrees. She was otherwise well (Figures 1a, b, c).

Her plain film X-rays showed her prior knee fusion and stump plasty with a dislocated and severely dysplastic hip joint (Figures $2 a$ and $b$ ).

The goals for her management were to provide her with a stable hip joint with adequate range of movement to allow functional mobility. It was decided that a customised proximal femoral replacement would be the most suitable option for the patient in view of these issues and her skeletal abnormality. The problems identified included the position and secure placement of the cup into a dysplastic acetabulum, and performing adequate contracture release while maintaining sufficient soft tissue balance to prevent hip dislocation and to provide motor function.

Work-up included a CT scan of the pelvis and right acetabulum in $1 \mathrm{~mm}$ axial slices (Figure 3). The postimaging processing could be used to provide more information on bone defects and stock.
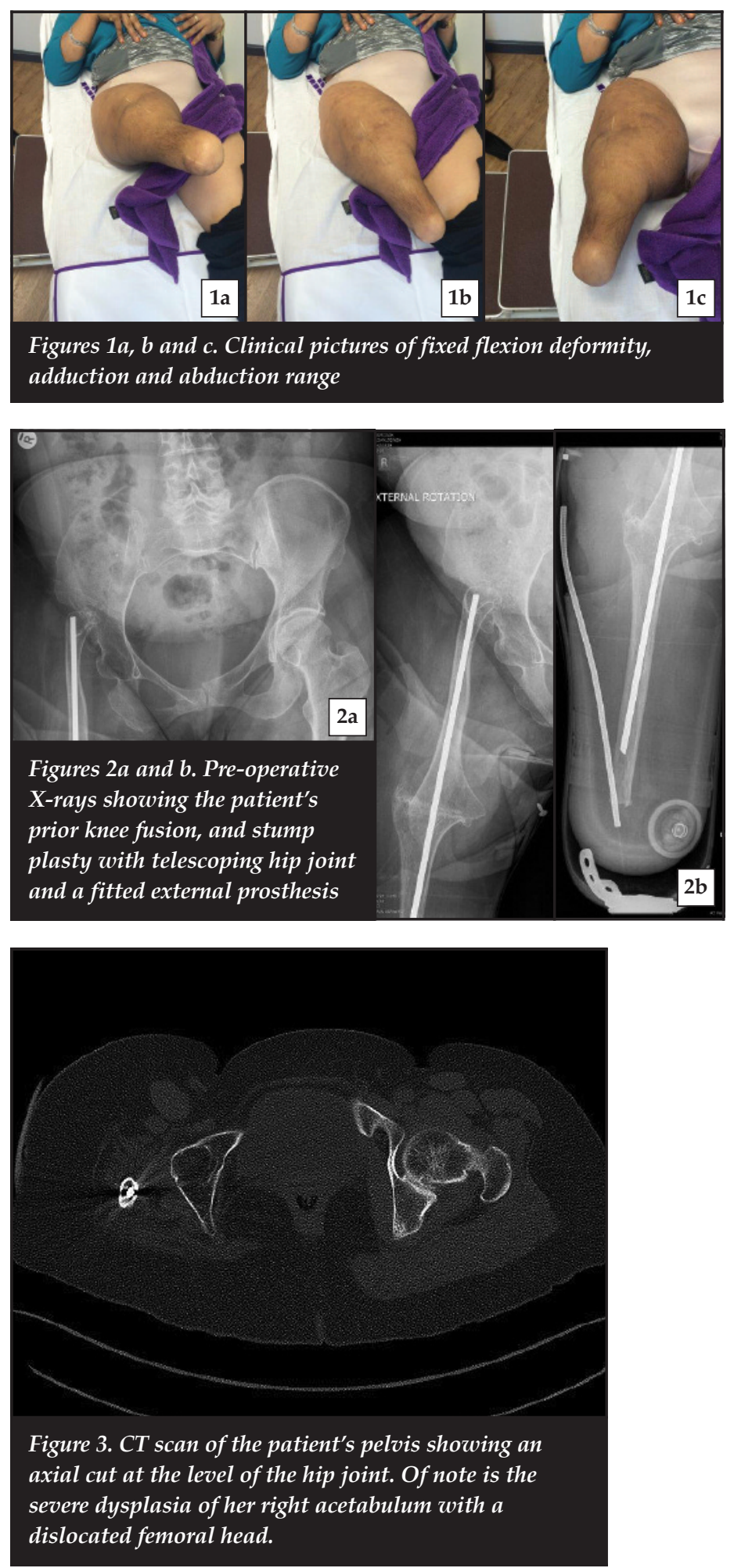

The CT DICOM data was then converted into stereolithography (.stl) file format and imported into Solidworks 3D Computer Aided Design (CAD) Software (Dassault Systemes). The resultant bone models were then used to design a suitable prosthesis, as well as the templates and jigs 
required for the insertion of the implant (LRS Implants, Cape Town). Plastic models of the pelvis and the implant were printed for final approval by the surgeon (Figures $4 a$ and $b$ ).

Once approval was given, the custom acetabular component was manufactured from Ti6Al4V powder using Electron Beam Melting (EBM, Pro-Fit, Germany). The use of EBM, which is a form of additive manufacturing (3D Printing), facilitated rapid, costeffective manufacture of the customised component that would not have been possible using conventional machining techniques. The proximal femoral component was produced using a combination of conventional milling and turning processes (Figures $5 a$ and $b$ ).

The customised acetabular component was designed to have both superior and inferior screw fixation into the pelvis. It was engineered to facilitate the cementation of a dual mobility cup (Zimmer-Biomet Avantage) into the acetabular component. Trabecular Ti6Al4V surfaces were incorporated onto the backside of the acetabular component to encourage bone in-growth for superior fixation. Custom-made jigs were used to ensure the correct reaming position of the new acetabulum and placement of the screws (Figures 6a and $b$ ).

The surgery was performed with the patient bolstered in the lateral position and a lateral approach was used to gain access to the hip joint. After removal of existing hardware and the proximal femur, the novel acetabulum was created using the premade reaming jigs. The acetabular component was fitted into this structure using screws accurately placed by the customised drill guide (Figures $7 a$ and $b$, and Figure 8). An Avantage dual-mobility cup was cemented into the acetabular component and a proximal femur replacement (LRS Implants, Cape Town) was performed with repair of the soft tissues. ${ }^{7}$

We followed up on this patient one year after the operation. She scored a fair score (14/30) on her Musculoskeletal Society Tumour Score (MSTS) patient-related outcome measure (PROM) and showed good range of movement at the hip joint with values of: flexion $90^{\circ}$; extension $10^{\circ}$; abduction $45^{\circ}$; adduction $15^{\circ}$; internal rotation $20^{\circ}$; external rotation $20^{\circ}$. She presented with no fixed flexion deformity of the hip joint. She did not complain of pain at her hip joint or surgical site but was not happy with her prosthesis, which caused her a moderate degree of pain. She was happy with the appearance of her leg.

\section{Discussion}

The combination of improved imaging and computer software in medicine together with advances in rapid prototyping has facilitated the development of customised implants to solve complex surgical problems. ${ }^{4,89}$ The many uses of this technology include surgical planning, implant- and tissue-designing, medical research, and medical education and training. ${ }^{4}$

Revision surgery and limb-reconstruction surgery are technically demanding., ${ }^{1,0-12}$ There are many problems such as distorted soft tissue and bony anatomy, variable bone stock and quality, and prosthetic placement. All of these difficulties were present in this case. Performing a complex joint reconstruction under these circumstances requires careful pre-operative planning in order to achieve accurate bony cuts and correct implant positioning and fixation.
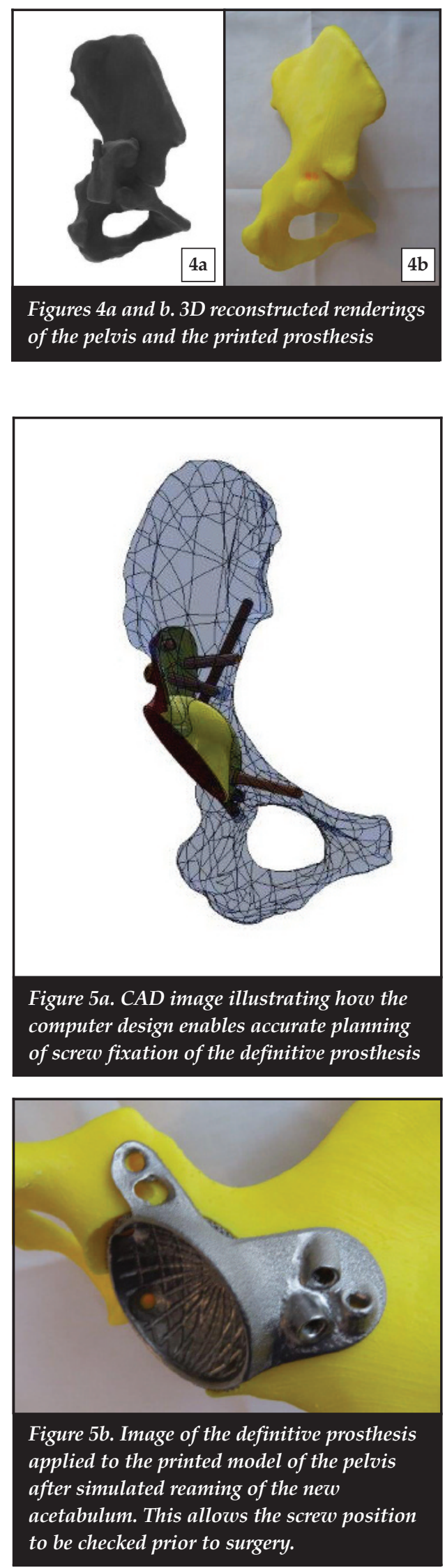


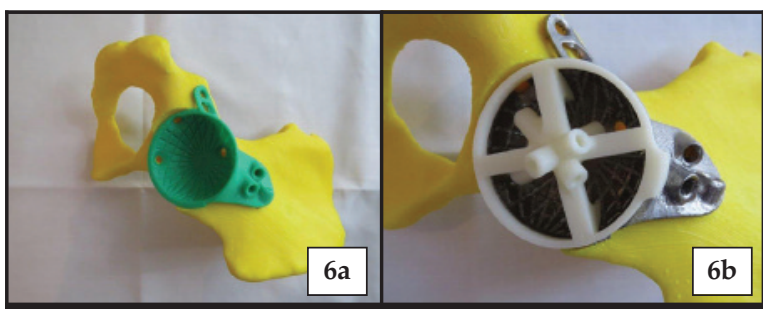

Figures $6 a$ and $b$. 3D printed jigs to guide acetabular reaming and screw placement. The jigs were printed with a 3D printer and are used to simulate the steps that would be taken intra-operatively. Figure $6 a$ would simulate the application of the definitive acetabular component (green) into which the screw guide (white) would be placed to guide the drilling of the screw holes. These two simulations would aid the surgeon in familiarising himself with the processes that would take place and ensure the jigs were correct in the placement of the acetabular component and screw placement.

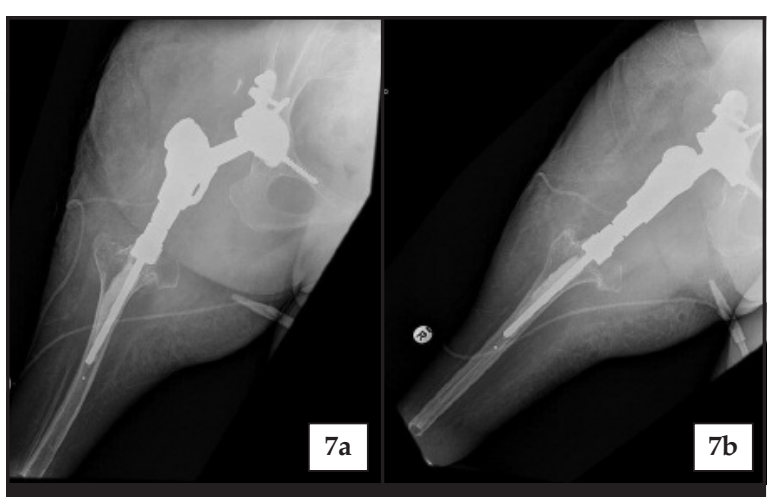

Figures $7 a$ and $b$. Post-operative X-rays showing final implant. Of note is the accurate placement of screws into the superior pubic ramus and ilium as well as the correct placement and fixation of the acetabular component. The figures also illustrate the proximal femoral replacement cemented into the cut end of the original knee arthrodesis. It also shows the attachments for the iliopsoas and abductor complexes to the proximal femoral replacement.

The precise extent of bone deformity is difficult to assess from conventional imaging, especially in a complex structure such as the pelvis, and standard prostheses may often be inadequate to allow proper placement and stable fixation. ${ }^{2,13,14}$ In response to these two problems, customised implants with the addition of plates, shaped specifically for the altered anatomy, and jigs to aid in the accurate placement of screws, have been developed., ${ }^{2,12}$

In the case report described above the goals of the surgery were to provide a pain-free, stable hip joint with an improved range of motion to allow for prosthetic use. The problems faced included the patient's dysplastic acetabulum and soft tissue contracture. The instruments required to perform this surgery together with the overall planning of the optimal surgical approach demand precise

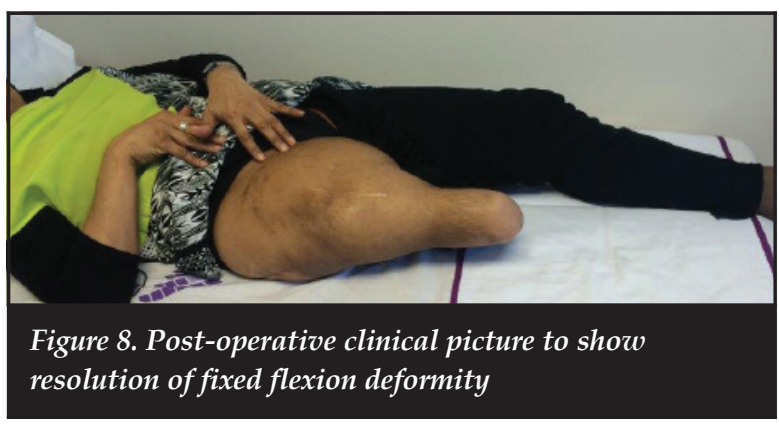

knowledge of bony dimensions and local variations in shape. ${ }^{1}$ The utilisation of CT scan data and the $3 \mathrm{D}$ printing of the bony anatomy provides the surgeon with an accurate representation of what is present and establishes a good basis for planning the surgery.

The initial planning phase (Figure 4) involved producing models of the pelvis in its current form. This was to assess the amount and position of available bone stock in order to plan the position of the acetabular cup and screws. Not only are these models able to supply quantitative and qualitative data on the acetabular defect but they also allow for a surgical rehearsal. ${ }^{2}$ The rehearsal allows for simulating all the complicated surgical steps in advance and can help the surgeon to anticipate possible intra-operative complications. ${ }^{4}$ This will help to reduce theatre time and allow for a smoother procedure.

The second phase (Figures 5 and 6) concerned the method with which to effect the surgery simply and accurately. A jig was printed using a $3 \mathrm{D}$ printer that would fit onto the contour of the native acetabulum and guide the reaming of the novel hip joint. The acetabular implant is fitted into this reamed cavity. Into this would fit a second jig which would act as a drill guide for the predetermined placement of screws through the prosthesis and into good pelvic bone.

Further advantages of this type of planning reduces the amount of backup equipment and implant options often required for the complex cases. ${ }^{12}$ Furthermore, with a better appreciation of the location of bone stock and defects, maximal host-bone contact is achieved without the use of structural allografts. ${ }^{2}$

Disadvantages of this method include the increased cost of the CT scan and printed models. However, these costs can be offset with reduced theatre time and allograft use, smaller inventory of implants, and a decreased revision rate. ${ }^{2}$

This process enabled a difficult surgery to be transformed into a manageable one by using accurate and well-fixed components with confidence. The surgery was performed a year ago and the patient has been fitted with an external prosthesis which allows independent pain-free functioning to date.

This software and technology is used extensively in orthopaedic oncology. It has many other potential uses, ranging from primary arthroplasty to complex trauma such as pelvic fractures. ${ }^{4}$ As the availability of this method of performing surgery increases, its use will become more frequent. The rapid prototyping technique 
is beneficial not only for bone reconstructions but also for replacing soft tissues such as an auricular prosthesis. Future applications may include the production of soft tissue scaffolds for cellular growth or even entire artificial organs adapted to the anatomy and needs of individual patients. ${ }^{4}$

\section{Compliance with ethics guidelines}

\section{Conflict of interest statement}

Each author certifies that he or she has no commercial associations that might pose a conflict of interest in connection with the submitted article.

\section{Ethics Review Committee Statement}

None required. Email consent was obtained from the patient for the case report. Work for the article was performed at Groote Schuur Hospital and Vincent Pallotti Life Orthopaedic Hospital.

\section{Disclosure}

Dr Keith Hosking is a medical advisor to LRS Implants, Cape Town but receives no financial compensation from the company. Mr Neil Campbell is the biomedical engineer for LRS Implants, Cape Town.

\section{References}

1. Potamianos $\mathrm{P}$, et al. Rapid prototyping for orthopaedic surgery. Proc Inst Mech Eng H, 1998;212(5):383-93.

2. John JF, Talbert RF, Taylor JK, Bargar WL. Use of acetabular models in planning complex acetabular reconstructions. J. Arthroplasty, October 1995;10(5):661-66.

3. $\mathrm{Wu} \mathrm{XB}$, et al. Printed three-dimensional anatomic templates for virtual preoperative planning before reconstruction of old pelvic injuries: initial results. Chin Med J (Engl), 2015;128(4):477-82.

4. Rengier F, et al. 3D printing based on imaging data: review of medical applications. Int J Comput Assist Radiol Surg, 2010;5(4):335-41.
5. Gouin F, et al. Computer-Assisted Planning and PatientSpecific Instruments for Bone Tumor Resection within the Pelvis: A Series of 11 Patients. Sarcoma, 2014;2014:842709.

6. Truscott M, de Beer DJ, Vicatos G, Hosking K, Barnard L, Booysen G, Campbell RI. Using RP to promote collaborative design of customised medical implants. Rapid Prototyping Journal, 2007;13(2):107-14.

7. Fresard PL, et al. Seven-year results of a press-fit, hydroxyapatite-coated double mobility acetabular component in patients aged 65 years or older. Eur J Orthop Surg Traumatol, 2013;23(4):425-29.

8. D'Urso PS, et al. Custom cranioplasty using stereolithography and acrylic. Br J Plast Surg, 2000;53(3):200-204.

9. Kim MS, Hansgen AR, Carroll JD. Use of rapid prototyping in the care of patients with structural heart disease. Trends Cardiovasc Med, 2008;18(6):210-16.

10. Morrey BF, Bryan RS. The Elbow/revision. Joint Replacement Arthroplasty, 1991; ch. 25, pp. 345-60.

11. Morrey BF, Kavanagh BF. Complications with revision of the femoral component of total hip arthroplasty. Comparison between cemented and uncemented techniques. J Arthroplasty, 1992;7(1):71-79.

12. Baauw $\mathrm{M}$, et al. The accuracy of positioning of a custommade implant within a large acetabular defect at revision arthroplasty of the hip. Bone Joint J, 2015;97-B(6):780-85.

13. Tanzer M, et al. Revision of the acetabular component with an uncemented Harris-Galante porous-coated prosthesis. J Bone Joint Surg Am, 1992;74(7):987-94.

14. McGurk M, et al. Rapid prototyping techniques for anatomical modelling in medicine. Ann R Coll Surg Engl, 1997;79(3):169-74..

This article is also available online on the SAOA website (www.saoa.org.za) and the SciELO website (www.scielo.org.za). Follow the directions on the Contents page of this journal to access it. 